TITLE:

\title{
Two-step supercritical dimethyl carbonate method for biodiesel production from Jatropha curcas oil.
}

\section{$\operatorname{AUTHOR}(\mathrm{S}):$}

Ilham, Zul; Saka, Shiro

\section{CITATION:}

Ilham, Zul ... [et al]. Two-step supercritical dimethyl carbonate method for biodiesel production from Jatropha curcas oil.. Bioresource technology 2009, 101(8): 2735-2740

\section{ISSUE DATE:}

2009-11-19

URL:

http://hdl.handle.net/2433/93459

\section{RIGHT:}

c 2009 Elsevier Ltd. All rights reserved.; この論文は出版社版でありませ ん。引用の際には出版社版をご確認ご利用ください。; This is not the published version. Please cite only the published version. 


\title{
Two-Step Supercritical Dimethyl Carbonate Method for Biodiesel Production from Jatropha curcas Oil
}

\author{
Zul Ilham and Shiro Saka* \\ Department of Socio-Environmental Energy Science, Graduate School of Energy Science, \\ Kyoto University, Yoshida-honmachi, Sakyo-ku, Kyoto 606-8501, Japan
}

*Corresponding author:

Shiro Saka

Department of Socio-Environmental Energy Science, Graduate School of Energy Science, Kyoto University, Yoshida-honmachi, Sakyo-ku, Kyoto 606-8501, Japan

Tel : +81-75-753-4738

Fax: +81-75-753-4738

E-mail address: saka@energy.kyoto-u.ac.jp 


\begin{abstract}
This study reports on a novel two-step process for biodiesel production consisting of hydrolysis of oils in sub-critical water and subsequent supercritical dimethyl carbonate esterification. This process found to occur optimally at the subcritical water treatment $\left(270^{\circ} \mathrm{C} / 27 \mathrm{MPa}\right)$ for $25 \mathrm{~min}$ followed by a subsequent supercritical dimethyl carbonate treatment $\left(300^{\circ} \mathrm{C} / 9 \mathrm{MPa}\right)$ for $15 \mathrm{~min}$ to achieve a comparably high yield of fatty acid methyl esters, at more than 97wt\%. In addition, the fatty acid methyl esters being produced satisfied the international standard specifications for use as biodiesel fuel. This new process for biodiesel production offers milder reaction condition (lower temperature and lower pressure), non-acidic, non-catalytic and applicable to feedstock with high amount of free fatty acids such as crude Jatropha curcas Oil.
\end{abstract}

Keywords: biodiesel; fatty acid methyl esters; subcritical water; supercritical dimethyl carbonate 


\section{Introduction}

To date, biodiesel has been widely produced and used in many countries. Biodiesel, a clean fuel commonly derived by transesterification of either edible or non-edible oils with alcohol, is a comparable match to petroleum diesel. The current commercial biodiesel production method called the alkali-catalyzed method, transesterifies triglycerides in the presence of alkaline catalyst with methanol to produce fatty acid methyl esters (FAME). However, this method does not suit feedstock with high content of free fatty acids, which consume the catalyst to form saponified substance and reduce the yields of fatty acid methyl esters (Hawash et al., 2009). In order to overcome these problems, the one-step non-catalytic supercritical methanol process (Saka process) and two-step process (SakaDadan process) have been developed (Kusdiana and Saka, 2004; Saka and Kusdiana, 2001).

Furthermore, the increasing trend towards biodiesel production has also led to an extreme increase of glycerol as by-product. In Europe, glycerol price decreased tremendously due to extensive supply in the market and glycerol-producing chemical companies were extremely affected (Willke and Vorlop, 2004). Glycerol, accounts 10\% of mass of the feedstock, is recovered together in mixture with methanol, water and residues of the alkaline catalyst after the transesterification process. Several complicated purification processes have to be conducted for this mixture to recover the pure glycerol, and this makes the price ten times higher than the unpurified one. By considering the complicated process and its cost, the pursuit to recover pure glycerol is not an economical one.

To balance glycerol's availability and demand, attempts to utilize glycerol from biodiesel production in innovative new ways have been reported (Silva et al., 2009; Tang 
et al., 2009). However, it is superior if biodiesel production could produce less or no glycerol at all. In accordance to this, Saka and Isayama (2009) developed supercritical methyl acetate method to produce fatty acid methyl esters and triacetin, without producing glycerol. The mixture of fatty acid methyl esters and triacetin can be used entirely as biodiesel due to their miscibility and similar fuel properties (Saka and Isayama, 2009).

Similarly, our recent study has reported a new potential method for biodiesel production by utilizing supercritical dimethyl carbonate without using any catalyst. This one-step direct transesterification process could yield glycerol carbonate and citramalic acid as by-products apart from the abundantly available glycerol normally produced in the conventional method (Ilham and Saka, 2009). Although this method could produce the byproducts with higher values, the severe reaction conditions may become a major concern in industrial application.

Therefore, in this study, a potentially new milder alternative route via two-step biodiesel production process has been investigated based on the hydrolysis of tryglycerides in subcritical water and subsequent supercritical dimethyl carbonate esterification of fatty acids in a non-catalytic manner. Briefly, the supercritical dimethyl carbonate was incorporated into a two-step process for biodiesel process. In this paper, the results obtained by utilizing Jatropha curcas oil in such a two-step process will be discussed. 


\section{Materials and Methods}

\subsection{Materials and its treatment procedure}

The seeds of the physic nut (Jatropha curcas) which were harvested from Malaysia, kept in the ordinary room for two years, were the feedstock subjected in this present study. Powdered seed samples were prepared by crushing it in a biomass blender. It was then dried in an incubator oven at $105^{\circ} \mathrm{C}$ for one hour. Crude oil was extracted with hexane in a Soxhlet apparatus according to the standard methods for the Analysis of Fats, Oils and Related Materials No. 1.5 (JOCS, 1996). This extraction yielded 45\% oil. The extracted oil was then subjected to Sulfuric Acid-Methanol Method No. 2.4.1.1 to convert into their fatty acid methyl esters form prior to gas chromatographic (GC) analysis of its composition by Standard Method No. 2.4.2.1 (JOCS, 1996). This GC analysis was conducted by using Shimadzu GC-14B system equipped with a flame ionization detector (FID), polyethylene glycol column (30m x $0.25 \mathrm{~mm}, 0.25 \mu \mathrm{m}$ DB-WAX, J\&W Scientific Inc.), oven temperature at $210^{\circ} \mathrm{C}$, detector temperature at $250^{\circ} \mathrm{C}$, injection volume of $1 \mu \mathrm{L}$ and helium as carrier gas. Table 1 displays the fatty acid composition of the obtained crude oil. Since the crude oil contains $13.6 \%$ free fatty acids, their proportion of free fatty acids to fatty acids in oil is shown according to the Standard Method No. 2.3.1 (JOCS, 1996).

Dimethyl carbonate, methanol, various authentic compounds of fatty acid methyl esters, glyoxal and fatty acids such as palmitic, stearic, oleic, linoleic, and linolenic acids were obtained from Nacalai Tesque Inc. 


\subsection{Experimental procedures}

Experiments for the two-step process were carried out in a batch-type supercritical biomass conversion system as reported previously (Saka and Kusdiana, 2001).

In the first step which is the hydrolysis of tryglycerides to fatty acids, $1.0 \mathrm{~mL}$ of the Jatropha curcas oil was mixed with $4.0 \mathrm{~mL}$ of water in an Inconel-625 reaction vessel. This corresponds to the volumetric ratio of 1:4 of triglycerides to water (molar ratio 1:217). It was, then, heated to the designated temperatures by immersing it into a molten tin bath and later quenched into a water bath to stop the reaction. The obtained products were left for gravity settling. The upper portion consisted of fatty acids, while the lower portion was water containing glycerol. The upper portion was then evaporated to remove the existing water and used for the second step.

For the second step, fatty acids from the first step were charged into the reaction vessel for esterification process by supercritical dimethyl carbonate. Products from both steps were, then, analyzed by gel permeation chromatography (GPC) (Column: GF-310HQ, oven temperature: $40^{\circ} \mathrm{C}$, flow speed: $1 \mathrm{~mL} / \mathrm{min}$, mobile phase: acetone, detector: RID 10A) and high performance liquid chromatography (HPLC) (Column: Cadenza CD-C18, oven temperature: $40^{\circ} \mathrm{C}$, flow speed: $1 \mathrm{~mL} / \mathrm{min}$, mobile phase: methanol and water, detector: RID 10A). In order to design the optimum parameters, the authentic samples of fatty acids as standards were also used under the same conditions stated beforehand. Just as a comparison, FAME was also produced by the conventional alkali-catalyzed method (Kusdiana and Saka, 2004). The percentage weight of fatty acids and FAME being reported in this study refers to the percentage of yield recovered based on theoretical yield. 


\subsection{Fuel properties determination}

Fatty acid methyl esters being produced from Jatropha curcas oil were then subjected to the fuel properties tests such as kinematic viscosity, carbon residue, pour point, cloud point, cold filter plugging point, ignition point to oxidation stability. For kinematic viscosity, the test was made at $40^{\circ} \mathrm{C}$ on Automatic Kinematic Viscosity Measuring System AKV-201 in accordance to ASTM D445. Carbon residue was measured by Micro Carbon Residue Tester ACR-M3 in accordance to ASTM D4530. The pour point and cloud point were measured by a Mini Pour/Cloud Point Tester MPC-102 covering a range from $-60{ }^{\circ} \mathrm{C}$ to $51{ }^{\circ} \mathrm{C}$. This tester is in accordance with ASTM D2500 and ASTM D6749. Automated Cold Filter Plugging Point Tester AFP-102 was used to measure cold filter plugging point in accordance to ASTM D637 while Pensky-Martens Closed Cup Automated Flash Point Tester APM-7 was used to determine the ignition point. All this instrumentations were from TANAKA Scientific Limited, Tokyo (ASTM, 2007). Oxidation stability was studied in accordance with EN 14112 on Rancimat 743 (Methrom, Herisau, Switzerland) (EN 14112, 2003). For analysis of acid number, iodine value, ester, monoglyceride, diglyceride, triglyceride, total glycerol and water contents, all were made according to the European Standard Methods (CEN, 2003). 


\section{Results and Discussion}

3.1 First step: hydrolysis of tryglycerides in subcritical water to fatty acids

Hydrolysis of vegetable oils in subcritical or supercritical water to produce fatty acids has been studied earlier by many researchers (Holliday et al., 1997; King et al., 1999; Moeller, 1997). It offers environmentally friendly way to extract organic compounds with similar efficiency by using organic solvents. Subcritical water treatment utilizes hot water at temperatures ranging up to $374^{\circ} \mathrm{C}$, under high pressure to maintain water in the liquid state. The most important factor to dissolve non-polar triglycerides with water in this process is the dielectric constant, which is mostly dependent to temperature and pressure. Dielectric constant of water is about 80 at an ambient condition but decreases down to 27 at higher temperatures of $250-270^{\circ} \mathrm{C}$ and under the pressure of $20-27 \mathrm{MPa}$.

In this study, hydrolysis behaviors of Jatropha curcas oil were studied at temperatures/pressures ranging from $255^{\circ} \mathrm{C} / 25 \mathrm{MPa}$ to $350^{\circ} \mathrm{C} / 32 \mathrm{MPa}$. Fig. 1a shows the effect of the reaction conditions on the yields of fatty acids throughout the hydrolysis process. At high temperatures of $350^{\circ} \mathrm{C} / 32 \mathrm{MPa}$, complete conversion of Jatropha curcas oil to fatty acids could be achieved after 3 min reaction time. In order to get a similar yield at milder conditions of $300^{\circ} \mathrm{C} / 29 \mathrm{MPa}$ and $270^{\circ} \mathrm{C} / 27 \mathrm{MPa}$, it took $12 \mathrm{~min}$ and $25 \mathrm{~min}$, respectively. At lower temperature of $255^{\circ} \mathrm{C} / 25 \mathrm{MPa}$, only less than $80 \mathrm{wt} \%$ of fatty acids was recovered.

The mildest condition to obtain high yield of fatty acids from Jatropha curcas oil were considered at $270^{\circ} \mathrm{C} / 27 \mathrm{MPa}$ for 25 min reaction time. At the mild condition of $270^{\circ} \mathrm{C} / 27 \mathrm{MPa}$, this reaction time is slightly longer than the optimum reaction time (20min) for rapeseed (Kusdiana and Saka, 2004). 
The reaction was expected to proceed in a manner described in Fig. 1b. Tryglycerides were hydrolyzed in subcritical water to produce fatty acids and glycerol. After the reaction, two layers will form in the mixture where the upper portion contains fatty acids while the lower portion contains water with glycerol. Hydrolyzed oils in the form of fatty acids were then esterified in supercritical dimethyl carbonate in the second step.

In details, the reaction mechanism of triglycerides in subcritical water consisted of three stepwise reactions; triglycerides to diglycerides, diglycerides to monoglycerides and finally monoglycerides to glycerol where fatty acids was produced at each step. Therefore, high content of free fatty acids in the feedstock of Jatropha curcas oil contributes to the reasonably fast reaction time needed to achieve full conversion in a mild condition. It should be noted that, the reaction with high contents of free fatty acids feedstock is not suitable for conventional alkali-catalyzed method (Vicente et al., 2004).

Large excess of volumetric ratio was also needed in this reversible hydrolysis reaction at 1:4 of tryglycerides to water (molar ratio 1:217). Theoretically with reference to the stoichiometry, the reaction only needs the molar ratio of 3 . However, the molar ratio of 217 in water was used in this study as an optimum parameter and to ease the separation of hydrolyzed products from the water portion containing glycerol. A study by Kusdiana and Saka (2004) had previously highlighted in their study that if less ratio of water is used, the hydrolysis reaction will take longer time to reach the optimum yield and thus, increase the energy uptake of the whole process. 
3.2 Second step: esterification of fatty acids by supercritical dimethyl carbonate to fatty acid methyl esters

The hydrolyzed upper portion in the form of fatty acids from the first step was, then, treated by supercritical dimethyl carbonate according to the pre-designed optimum parameters. After the reaction, the mixture was settled into separable upper and lower portions. The upper portion containing several kinds of fatty acid methyl esters (FAME) were then analyzed and presented in Fig. 2. As a comparison, the yield of fatty acid methyl esters from fatty acids treated in supercritical methanol is presented together. By considering the difference in pressure, the yield of FAME from fatty acids treated in supercritical dimethyl carbonate $\left(300^{\circ} \mathrm{C} / 9 \mathrm{MPa}\right)$ is high such as at $97 \mathrm{wt} \%$ after $15 \mathrm{~min}$ reaction, which is comparable to the yield obtained by supercritical methanol (300 $\mathrm{C} / 20 \mathrm{MPa})$ (Kusdiana and Saka, 2004).

Based on the evidence obtained, the esterification of fatty acids in supercritical dimethyl carbonate was assumed to proceed in the reaction pathway where the fatty acid reacts with dimethyl carbonate to produce fatty acid methyl ester, glyoxal and water. HPLC analysis of the lower aqueous portion showed that the lower portion contains some glyoxal, as per compared with the authentic compounds.

Several fatty acids commonly present in Jatropha curcas oil such as oleic acid, linoleic acid and palmitic acid were also investigated by supercritical dimethyl carbonate esterification at $300^{\circ} \mathrm{C} / 9 \mathrm{MPa}$. From the HPLC analysis, all fatty acids peaks were observed in the early stage ( $<4 \mathrm{~min}$ ) of the reaction, but most peaks disappeared after $10 \mathrm{~min}$ of reaction time. It was clear from these results that the fatty acids available in Jatropha curcas oil could be fully converted into their corresponding fatty acid methyl esters by 
supercritical dimethyl carbonate esterification. This result constantly match the previous findings by Imahara et al. (2008), that exposure of methyl linoleate, an unsaturated fatty acid methyl esters at $300^{\circ} \mathrm{C} / 19 \mathrm{MPa}$ will not lead to the decomposition of its structure as long as the reaction does not exceed 20 min of reaction time. Methyl oleate, which is other major unsaturated fatty acid methyl esters in Jatropha curcas oil, was also found to be high in yield. It proves that the two-step process is good at reducing the possibility for structure decomposition of unsaturated fatty acids methyl esters.

\subsection{Pre-designed optimum parameters for supercritical dimethyl carbonate esterification}

In order to attain the maximum yields of fatty acid methyl esters, optimum reaction conditions for esterification in supercritical dimethyl carbonate were determined. Oleic acid, as the major constituent of fatty acid in Jatropha curcas oil, was used as a model fatty acid in this study.

In supercritical reaction, molar ratio of reactant to fatty acids plays an important role (Kusdiana and Saka, 2004). For alkali-catalyzed transesterification process, a molar ratio higher than optimum value reduces the yield and complicates the separation of esters and glycerol (Sharma, 2008). However, high molar ratio is needed for supercritical processes in order to increase contact area between oil and reactant. Fig. 3 shows the yield of methyl oleate, the corresponding fatty acid methyl esters for oleic acid treated at various molar ratios of dimethyl carbonate to fatty acids. Supercritical dimethyl carbonate esterification does proceed better at lower molar ratio, if compared to the transesterification reaction. At molar ratio of 7 , oleic acid was mostly converted to methyl 
oleate. The optimum molar ratio of dimethyl carbonate to fatty acid was determined at 14 due to the high yield of fatty acid methyl esters produced.

At the fixed molar ratio of 14:1 (dimethyl carbonate: oleic acid), the effect of temperature was studied between $270^{\circ} \mathrm{C}$ in $6 \mathrm{MPa}$ and $350^{\circ} \mathrm{C}$ in $19 \mathrm{MPa}$. The results are shown in Fig. 4. Yield of fatty acid methyl esters was the highest at $350^{\circ} \mathrm{C} / 19 \mathrm{MPa}$ and almost complete conversion was observed after 10 min of reaction time. The mildest condition was found at $300^{\circ} \mathrm{C} / 9 \mathrm{MPa}$, where the yield of fatty acid methyl esters was comparable with those at $320^{\circ} \mathrm{C} / 11 \mathrm{MPa} / 15 \mathrm{~min}$ and $350^{\circ} \mathrm{C} / 19 \mathrm{MPa} / 10 \mathrm{~min}$. At lower reaction temperature of $270^{\circ} \mathrm{C} / 6 \mathrm{MPa}$, the fatty acid methyl esters yield was as low as 40wt\% even after longer reaction time. It should be noted that the critical temperature for dimethyl carbonate is at $275^{\circ} \mathrm{C}$. The reaction pressure was not controllable in this process, as these studies were done by utilizing a batch reaction vessel. Therefore, reaction pressure is totally dependent to the type of reactant and reaction temperature.

\subsection{Biodiesel production process by two-step method}

Based on the results obtained from the first step and second step treatments as described previously, a two step biodiesel production process, i.e. hydrolysis followed by subsequent esterification in supercritical dimethyl carbonate, was proposed as shown in Fig. 5. In the first step, oil or fat were mixed with water and treated at subcritical condition of water $\left(270^{\circ} \mathrm{C} / 6 \mathrm{MPa}\right)$ for the hydrolysis reaction. The treated mixture was then separated to upper and lower portions. The upper portion contains fatty acids while the lower portion consists of water containing glycerol. The upper portion was then mixed with dimethyl carbonate and treated at supercritical condition $\left(300^{\circ} \mathrm{C} / 9 \mathrm{MPa}\right)$ for esterification reaction in 
the second step. Again, the treated mixture was then separated to the upper portion containing fatty acid methyl esters (biodiesel) while the lower portion consists of water containing glyoxal. Overall, this process yields biodiesel as a main product while glycerol and glyoxal were produced as by-products. The supercritical methanol process (Saka and Kusdiana, 2001) is probably the best candidate for the second step (Hawash et al., 2009) but in order to explore new potential reaction pathways, the utilization of supercritical dimethyl carbonate is therefore, justified in this study.

For an example, glyoxal, if could be extracted purely from the water portion, has a potential commercial application after conversion into glycolic acid and glyoxalic acid. They are highly valued fine chemicals which can be used in perfumery, flavour, pharmaceutical, and agrochemical industries (Yadav and Gupta, 2000).

\subsection{Potential of the two-step method for feedstock with high free fatty acids content}

To achieve a reasonable yield in alkali-catalyzed transesterification process, feedstock should contain minimum level of free fatty acids preferably less than $5 \%$. However, the feedstock in this study (Jatropha curcas oil) indicates higher content of free fatty acids, about $13.6 \%$. Thus, direct transesterification of these seed oils with basic alkaline catalyst will not be efficient due to the formation of the saponified products which contributes to complicated separation process and loss in the yield of methyl esters. Fatty acids could be esterified by acid catalyst (Lotero et. al, 2005) but the reaction took longer reaction time and the formation of water from esterification of fatty acids would reduce the catalytic activity. Based on the results obtained from this two-step supercritical method, 
the yield of fatty acid methyl esters was definitely higher and the high free fatty acids content in the feedstock did not affect the process.

In addition, as presented in Table 2, the fatty acid methyl esters from this two-step method exhibits suitable properties in accordance to the designated standard for use as biodiesel except for the specification stated for oxidation stability (EU) and carbon residue (US). Oxidation stability is an important parameter in order to ensure that the biodiesel will be stable against oxidation during storage to prevent denaturation and maintains its quality. The low oxidation stability of fatty acid methyl esters produced by two-step method does not represent the drawback of the process as it was contributed mainly due to the high level of unsaturated fatty acids in the feedstock. Apparently, the oxidation stability gets better with the decrease of unsaturation degree in biodiesel (Xin et al., 2008). For the carbon residue content, there has been no claim that an exceeding small amount of the carbon residue could lead to fuel injection clogging or fuel filter plugging (Monyem et al., 2000).

In our previous study, due to conditions in high temperature and high pressure of the supercritical fluid, thermal stability of fatty acid methyl esters and actual biodiesel prepared from various plant oils was studied in supercritical methanol over a range of its condition between $270^{\circ} \mathrm{C} / 17 \mathrm{MPa}$ and $380^{\circ} \mathrm{C} / 56 \mathrm{MPa}$ (Imahara et al., 2008). Since most of the plant oils contain high amount of poly-unsaturated fatty acids, it tends to be vulnerable to thermal degradation occurred in a reaction taking place at higher than $300^{\circ} \mathrm{C}$. The thermal degradation is a term describing the isomerization of from cis-type to trans-type and a difference between cis-type and trans-type methyl esters is reflected in the cold flow properties. Therefore, a high-quality biodiesel not only depends on the structure of the esters itself but also to the treatment and reaction affecting it in the production process. 


\subsection{Advantages of the two-step supercritical dimethyl carbonate methods}

The one-step process refers to a direct supercritical dimethyl carbonate transesterification (Ilham and Saka, 2009), while two-step process consists of hydrolysis in subcritical water and subsequent esterification in supercritical dimethyl carbonate. It was clearly demonstrated in Fig. 6 that the yield of fatty acid methyl esters from the two-step process was high enough at $97 \%$ and better in non-catalytic system, compared with the conventional alkali-catalyzed method (Kusdiana and Saka, 2004).

Furthermore, as presented in the schematic diagram (Fig. 5), the two-step process is a non-acidic process as it produced no internal organic acid in the course of the reaction. Less acidic process favors to the production of high quality fatty acid methyl esters for use as biodiesel (Zhang and Zhang, 2005). The whole two-step process employs hydrolysis of triglycerides in subcritical water at $270^{\circ} \mathrm{C} / 27 \mathrm{MPa}$ for $25 \mathrm{~min}$ followed by a subsequent supercritical dimethyl carbonate treatment at $300^{\circ} \mathrm{C} / 9 \mathrm{MPa}$ for $15 \mathrm{~min}$. Although the pressure is still high at $27 \mathrm{MPa}$, this condition could be justified as milder than other previous attempts (Ilham and Saka, 2009; Saka and Kusdiana, 2001).

Thus, these evidences support the claim that the two-step supercritical dimethyl carbonate process is a comparably excellent biodiesel production method in a non-catalytic manner. 


\section{Conclusions}

Contamination of free fatty acids in non-edible seed oils was common due to poor handling and storage in which the conventional alkali-catalyzed biodiesel production is not applicable. However, in this two-step process, high quality biodiesel could be produced out of feedstock with high free fatty acids contained such as Jatropha curcas oil.

Successful completion of reaction series in this study concludes that the process is good in yield and better in a non-catalytic supercritical process, if compared with the conventional alkali-catalyzed method. In addition, it is a non-acidic and mild enough not to deteriorate feedstock with high poly-unsaturated fatty acids. 


\section{References}

ASTM Standard (ASTM)., 2007. Standard test methods for D445, D4530, D2500, D6371, D93, D6749 and D6751 standards. West Conshoshocken, PA.

European Committee of Standardization (CEN)., 2003. Standard test methods for EN14103, EN14105, ENISO12937, EN14104, EN14111 and EN14214 standards. CEN, EU.

EN 14412. 2003. Fat and oil derivatives - FAME - Determination of oxidation stability (Accelerated oxidation test). CEN, EU.

Hawash, S., Kamal, N., Zaher, F., Kenawi, O., El Diwani, G., 2009. Biodiesel fuel from Jatropha oil via non-catalytic supercritical methanol transesterification. Fuel 88, 579-582.

Holliday, R.L., King, J.W., List, G.R., 1997. Hydrolysis of vegetable oils in sub- and supercritical water. Ind. Eng. Chem. Res. 36, 932-935.

Ilham, Z., Saka, S., 2009. Dimethyl carbonate as potential reactant in non-catalytic biodiesel production by supercritical method. Bioresour. Technol. 100, 1793-1796.

Imahara, H., Minami, E., Hari, S., Saka, S., 2008. Thermal stability of biodiesel in supercritical methanol. Fuel 87, 1-6.

Japan Industrial Standard Committee (JIS)., 2008. Fatty acid methyl esters (FAME) standards for use as automotive fuel (in Japanese)-JIS K2390. JIS, Japan.

Japan Oil Chemists’ Society (JOCS)., 1996. Standard methods for fats, oils and related Materials (in Japanese). JOCS, Japan.

King, J.W., Holliday, R.L., List, G.J., 1999. Hydrolysis of soybean oil in subcritical water flow reactor. Green Chem. 1, 261-264.

Kusdiana, D., Saka, S., 2004. Two-step preparation for catalyst-free biodiesel fuel production: Hydrolysis and methyl esterification. Appl. Biochem. Biotech. 113-116, 781791.

Lotero, E., Liu, Y.J., Lopez, D.E., Suwannakaran, K., Bruce, D.A., Goodwin, J.G., 2005. Synthesis of biodiesel via acid catalysis. Ind. Eng. Chem. Res. 44, 5353-5363.

McCormick, R.L., Ratcliff, M., Moens, L., Lawrence, R., 2007. Several factors affecting the stability of biodiesel in standard accelerated test. Fuel Process. Technol. 88, 651-657.

Moeller, P., 1997. A method for splitting fats and other esters by hydrolysis. International patent WO9707187. 
Monyem, A., Canakci, M., Gerpen J.H.V., 2000. Investigation of biodiesel thermal stability under simulated in-use conditions. Appl. Eng. Agric. 16, 373-378.

Saka, S., Isayama, Y., 2009. A new process for catalyst-free production of biodiesel using supercritical methyl acetate. Fuel doi:10.1016/j.fuel.2008.12.028.

Saka, S., Kusdiana, D., 2001. Biodiesel fuel from rapeseed oil as prepared in supercritical methanol. Fuel 80, 225-231.

Sharma, Y.C., Singh, B., 2008. Development of biodiesel: current scenario. Renew. Sustain. Energy Rev. doi:10/1016/j.rser.2008.08.009.

Silva, G.P.D., Mack, M., Contiero, J., 2009. Glycerol: a promising and abundant carbon source for industrial microbiology. Biotechnol. Adv. 27, 30-39.

Tang, S., Boehme, L., Lam, H., Zhang, Z., 2009. Pichia pastoris fermentation for phytase production using crude glycerol from biodiesel production as the sole carbon source. Biochem. Eng. Jour. 43, 157-162.

Vicente, G., Martinez, M., Aracil, J., 2004. Integrated biodiesel production: a comparison of different homogenous catalyst systems. Bioresour. Technol. 92, 297-305.

Willke, T.H., Vorlop, K.D., 2004. Industrial bioconversion of renewable resources as an alternative to conventional chemistry. Appl. Microbiol. Biotechnol. 66, 135-145.

Xin, J., Imahara, H., Saka, S., 2008. Oxidation stability of biodiesel fuel as prepared by supercritical methanol. Fuel 87, 1807-1813.

Yadav, G.D., Gupta, V.R., 2000. Synthesis of glyoxalic acid from glyoxal, Proc. Biochem. 36, 73-78.

Zhang, S., Zhang, C.Z., 2005. Novel process to produce branched fatty acid/ester for biodiesel and new surfactant applications. In: The Proceeedings of the $3^{\text {rd }}$ International Conference on Functional Molecules, Dalian, China, pp. 343-346. 


\section{Figure Captions}

Fig. 1. a) Changes in the yield of fatty acids as Jatropha curcas oil treated in subcritical water at different conditions (volumetric ratio of tryglycerides to water=1:4).

b) Reaction scheme for hydrolysis of tryglycerides in sub-critical water into fatty acids and glycerol. $\mathrm{R}^{1}, \mathrm{R}^{2}$ and $\mathrm{R}^{3}$ : Hydrocarbon residues.

Fig. 2. Yields of fatty acid methyl esters from fatty acids (upper portion) as treated in supercritical dimethyl carbonate at $300^{\circ} \mathrm{C} / 9 \mathrm{MPa}$ and supercritical methanol at $300^{\circ} \mathrm{C} / 20 \mathrm{MPa}$ for comparison.

Fig. 3. Effect of molar ratio of oleic acid to dimethyl carbonate on yield of fatty acid methyl esters as treated at $300^{\circ} \mathrm{C} / 9 \mathrm{MPa}$. Dashed line represents data from transesterification by supercritical dimethyl carbonate (Ilham and Saka, 2009).

Fig. 4. Yield of oleic acid treated in supercritical dimethyl carbonate at various temperatures (dimethyl carbonate/oleic acid $=14 / 1(\mathrm{~mol} / \mathrm{mol})$ ).

Fig. 5. Schematic biodiesel production process by the two-step method (hydrolysis in subcritical water and subsequent supercritical dimethyl carbonate esterification).

Fig. 6. The yield of fatty acid methyl esters by the non-catalytic two-step supercritical dimethyl carbonate method $\left(270^{\circ} \mathrm{C} / 27 \mathrm{MPa} / 25 \mathrm{~min}\right.$ and subsequent $\left.300^{\circ} \mathrm{C} / 9 \mathrm{MPa}\right)$. The reaction time is a sum for both hydrolysis time in subcritical water and subsequent supercritical dimethyl carbonate esterification time. 
a)

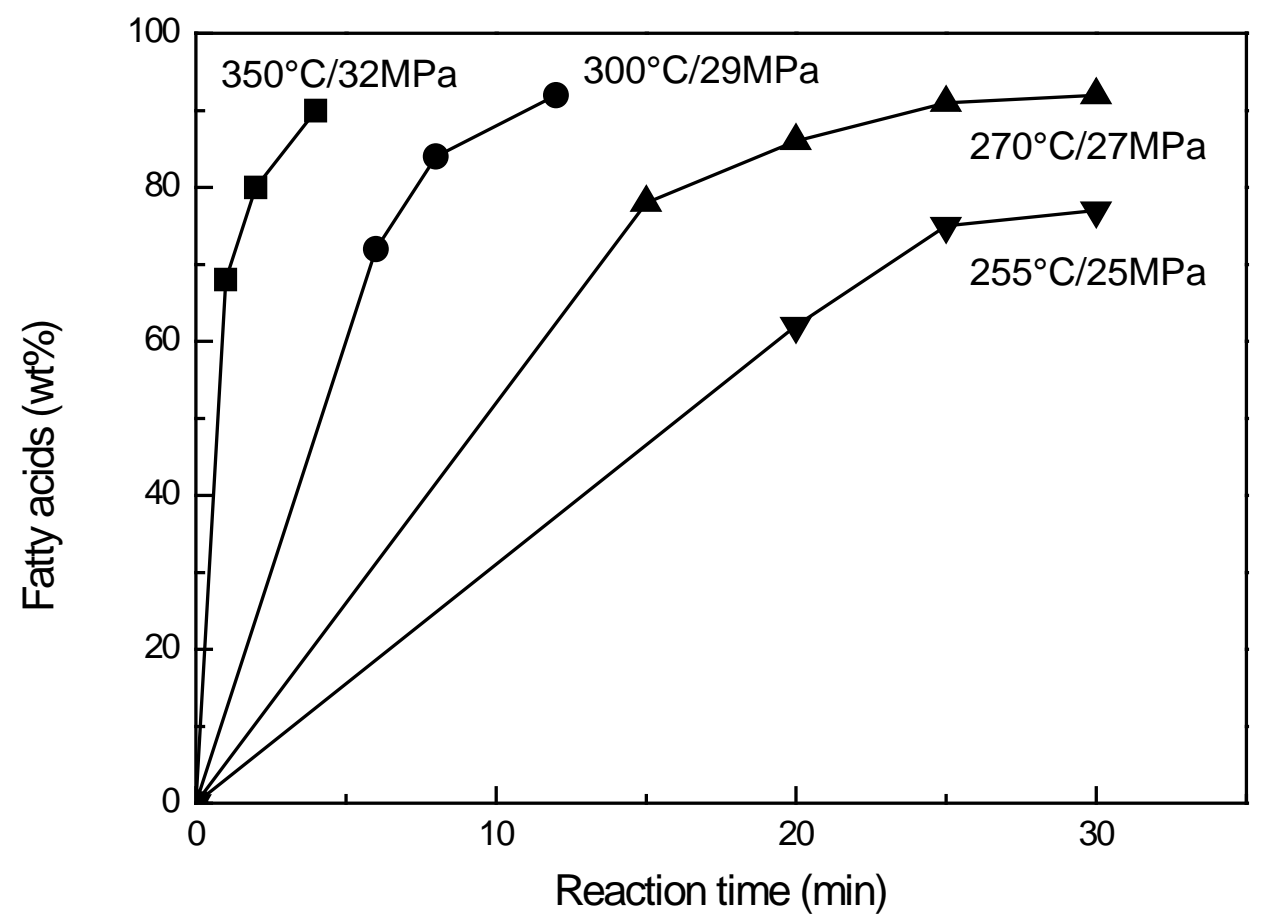

b)

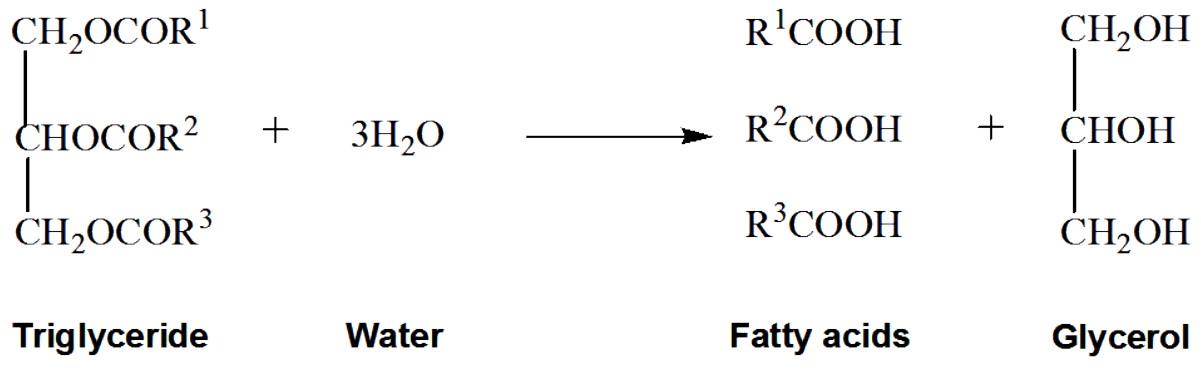

Fig. 1. a) Changes in the yield of fatty acids as Jatropha curcas oil treated in subcritical water at different conditions (volumetric ratio of tryglycerides to water=1:4).

b) Reaction scheme for hydrolysis of tryglycerides in sub-critical water into fatty acids and glycerol. $\mathrm{R}^{1}, \mathrm{R}^{2}$ and $\mathrm{R}^{3}$ : Hydrocarbon residues. 


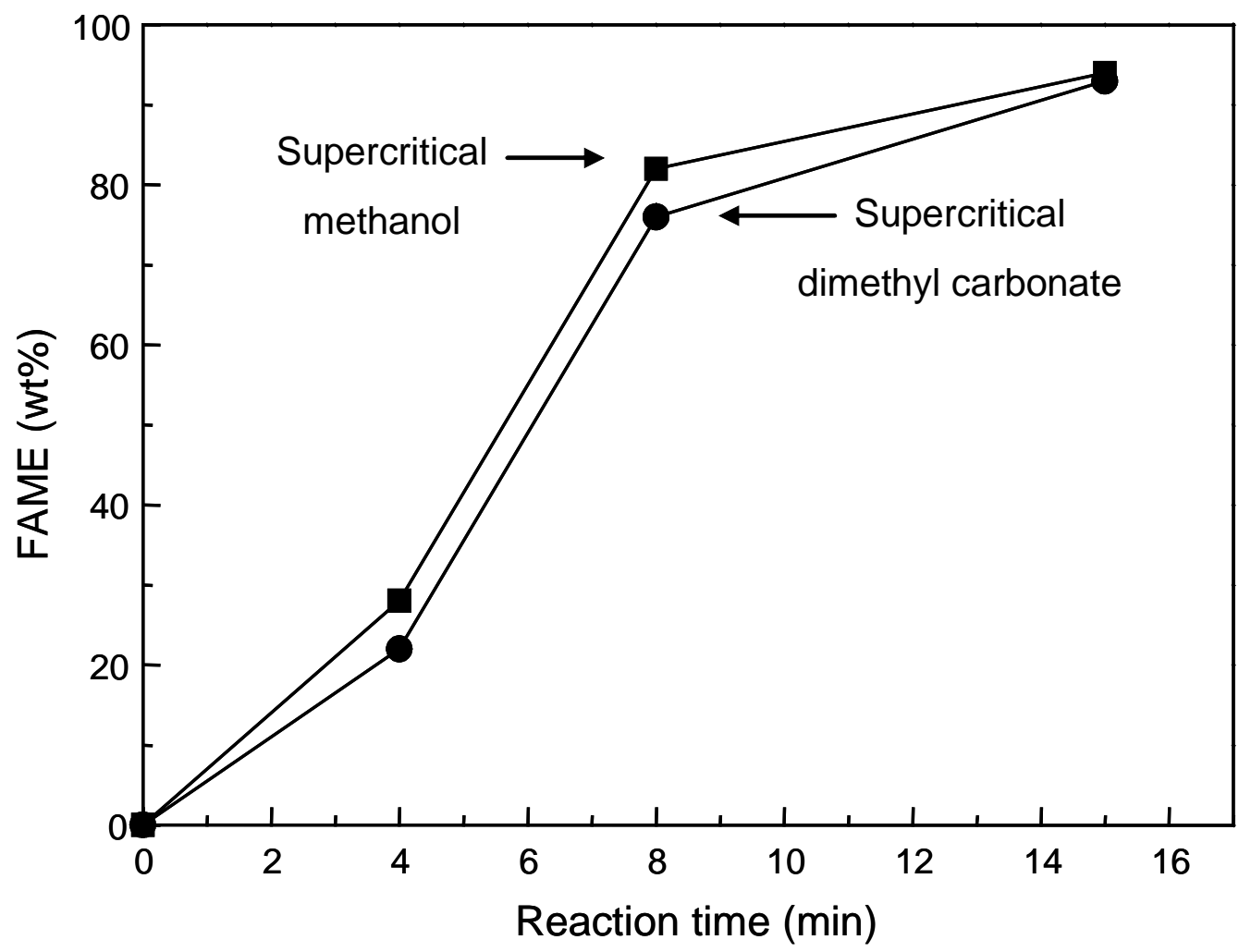

Fig. 2. Yields of fatty acid methyl esters from fatty acids (upper portion) as treated in supercritical dimethyl carbonate at $300^{\circ} \mathrm{C} / 9 \mathrm{MPa}$ and supercritical methanol at $300^{\circ} \mathrm{C} / 20 \mathrm{MPa}$ for comparison. 


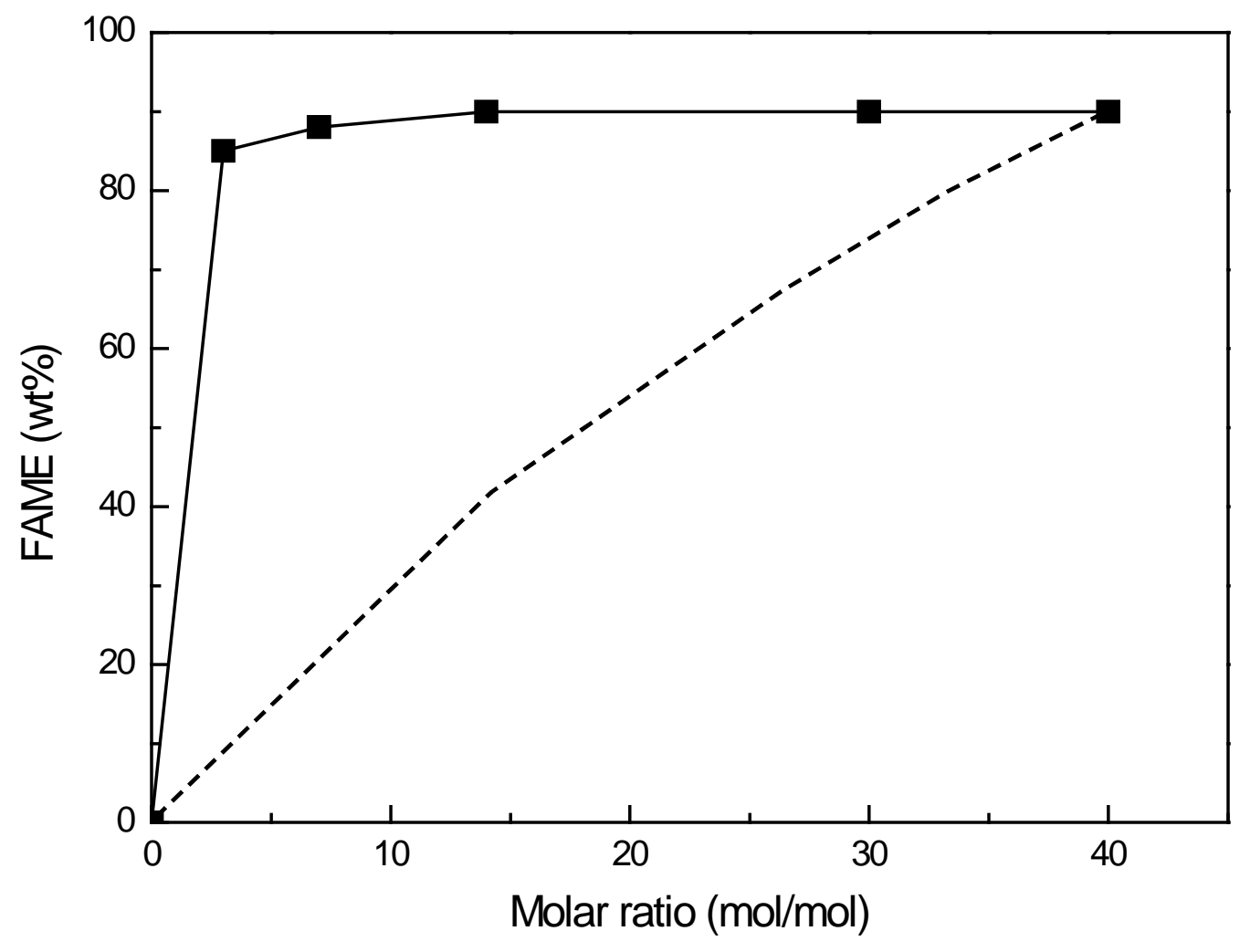

Fig. 3. Effect of molar ratio of oleic acid to dimethyl carbonate on yield of fatty acid methyl esters as treated at $300^{\circ} \mathrm{C} / 9 \mathrm{MPa}$. Dashed line represents data from transesterification by supercritical dimethyl carbonate (Ilham and Saka, 2009; Saka and Kusdiana, 2004). 


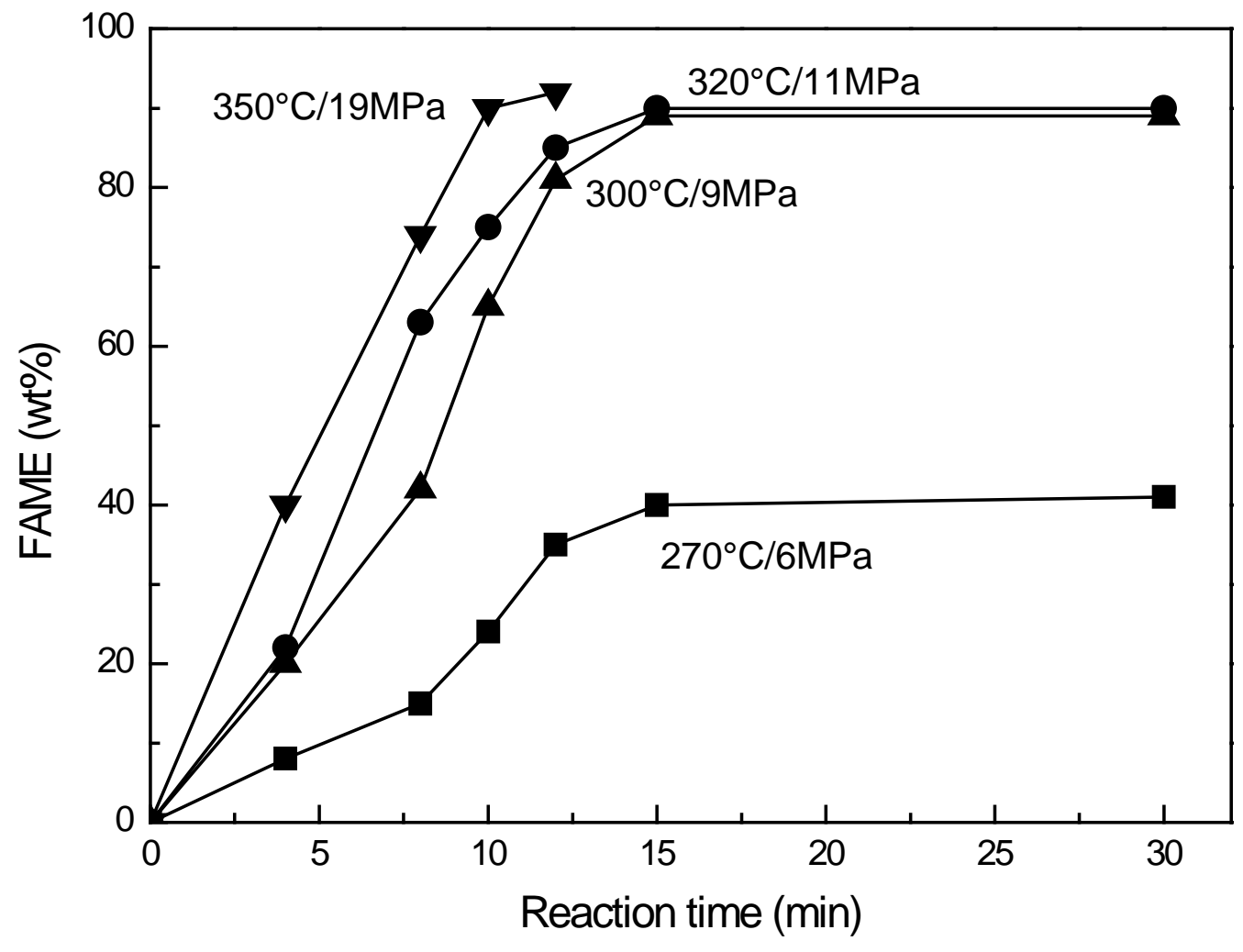

Fig. 4. Yield of oleic acid treated in supercritical dimethyl carbonate at various conditions (dimethyl carbonate/oleic acid = 14/1 ( $\mathrm{mol} / \mathrm{mol})$ ). 


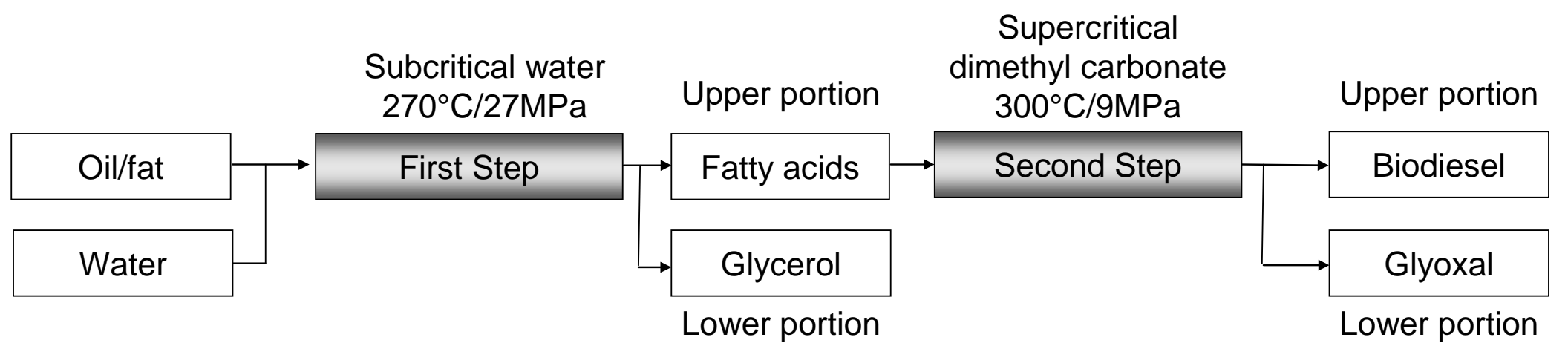

Fig. 5. Schematic biodiesel production process by the two-step supercritical dimethyl carbonate method (hydrolysis in sub-critical water and subsequent supercritical dimethyl carbonate esterification). 


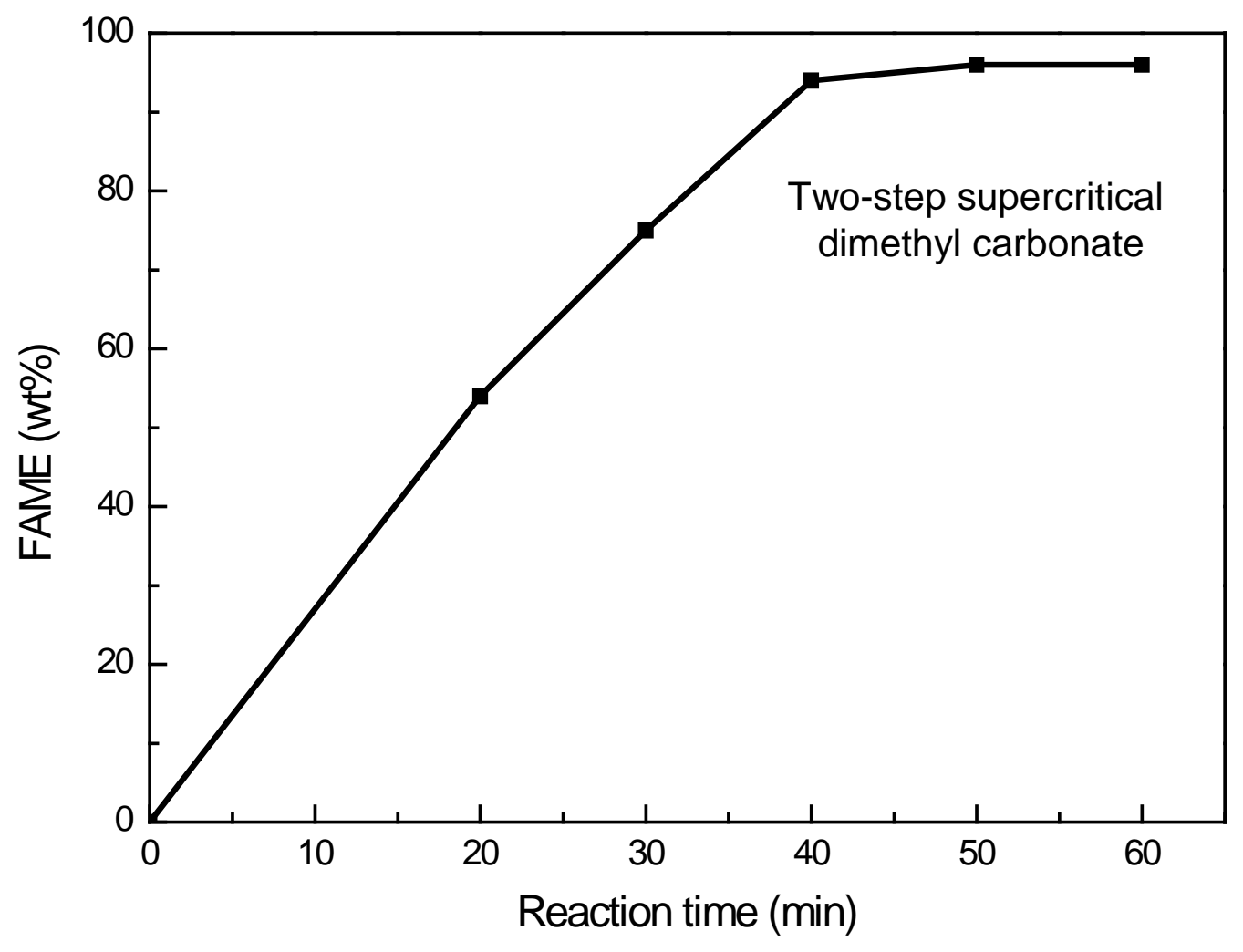

Fig. 6. The yield of fatty acid methyl esters by the non-catalytic two-step supercritical dimethyl carbonate method $\left(270^{\circ} \mathrm{C} / 27 \mathrm{MPa}\right.$ and subsequent $\left.300^{\circ} \mathrm{C} / 9 \mathrm{MPa}\right)$ 
Table 1 Fatty acid composition of crude Jatropha curcas oil

\begin{tabular}{lcccc}
\hline \multicolumn{1}{c}{ Fatty acid $^{\mathrm{a}}$} & & Crude oil (wt\%) & Free fatty acid (wt\%) & Proportion of free fatty acid (\%) \\
\hline Myristic acid & $14: 0$ & 0.1 & - & - \\
Palmitic acid & $16: 0$ & 13.3 & 1.4 & 10.5 \\
Stearic acid & $18: 0$ & 5.8 & 0.2 & 3.4 \\
Arachidic acid & $20: 0$ & 0.3 & - & - \\
Behenic acid & $22: 0$ & 0.2 & - & - \\
Palmitoleic acid & $16: 1$ & 1.0 & - & - \\
Oleic acid & $18: 1$ & 51.0 & 4.8 & 2.4 \\
Linoleic acid & $18: 2$ & 28.0 & 7.2 & - \\
Linolenic acid & $18: 3$ & 0.3 & - & - \\
\hline Total & - & 100 & 13.6 & -
\end{tabular}

${ }^{\mathrm{a}}$ The former number represents the one of the carbons in the hydrocarbon chain while the latter the number of the double bond in fatty acid. 
Table 2 Properties of fatty acid methyl esters (FAME) prepared from crude Jatropha curcas oil for use as biodiesel in comparison with international standards ${ }^{\mathrm{a}}$

\begin{tabular}{|c|c|c|c|c|c|c|}
\hline Properties & Method & Unit & $\begin{array}{c}\text { FAME } \\
\text { (Biodiesel) }\end{array}$ & $\begin{array}{c}\text { Japan } \\
\text { (JIS K2390) }\end{array}$ & $\begin{array}{c}\text { EU } \\
(\text { EN 14214) }\end{array}$ & $\begin{array}{c}\text { US } \\
\text { (ASTM D6751-07) }\end{array}$ \\
\hline Carbon residue & ASTM D4530 & wt\% & 0.15 & $\leq 0.30$ & $\leq 0.30$ & $\leq 0.05$ \\
\hline Cold filter plugging point & ASTM D6371 & ${ }^{\circ} \mathrm{C}$ & -3.2 & - & - & - \\
\hline Ignition point & ASTM D93 & ${ }^{\circ} \mathrm{C}$ & 162.5 & $\geq 120$ & $\geq 101$ & $\geq 130$ \\
\hline Cloud point & ASTM D6749 & ${ }^{\circ} \mathrm{C}$ & -3.0 & - & - & - \\
\hline Monoglyceride & EN 14105 & $\mathrm{wt} \%$ & 0.2 & $<0.80$ & $<0.80$ & - \\
\hline Diglyceride & EN 14105 & wt\% & 0.07 & $<0.20$ & $<0.20$ & - \\
\hline Triglyceride & EN 14105 & $\mathrm{wt} \%$ & n.d. ${ }^{b}$ & $<0.20$ & $<0.20$ & - \\
\hline Total glycerol content & EN 14105 & wt\% & 0.08 & $<0.25$ & $<0.25$ & $<0.24$ \\
\hline Water content & EN ISO12937 & $\mathrm{mg} / \mathrm{kg}$ & 302 & $<500$ & $<500$ & $<500$ \\
\hline Acid number & EN 14104 & $\mathrm{mg}(\mathrm{KOH}) / \mathrm{g}$ & 0.1 & $<0.50$ & $<0.50$ & $<0.50$ \\
\hline
\end{tabular}

${ }^{\mathrm{a}}$ JIS (2008); CEN (2003); ASTM (2007).

${ }^{\mathrm{b}}$ n.d., not detectable. 